\title{
Climate change adaptation (CCA) research in Nepal: implications for the advancement of adaptation planning
}

\author{
Gyanendra Karki ${ }^{1} \cdot$ Balram Bhatta $^{1} \cdot$ Naba R. Devkota $^{2} \cdot$ Ram P. Acharya $^{3}$. \\ Ripu Mardhan Kunwar ${ }^{4}$ (D)
}

Received: 12 August 2021 / Accepted: 22 December 2021 / Published online: 11 February 2022

(C) The Author(s), under exclusive licence to Springer Nature B.V. 2022

\begin{abstract}
Climate change has become one of the most compelling fields of empirical research over the last couple of decades, partly due to its socio-economic impacts. Using a meta-analysis of 235 peer-reviewed articles published between January 2010 and July 2020, this paper appraises climate change adaptation (CCA) research in Nepal and draws lessons for future adaptation planning. The number of research is observed to have increased significantly in recent years (2015-2020) although there is no consistent pattern over the review period and at the thematic level. Findings submit that the agriculture and food security has the highest number of publications (37\%) followed by gender equality and social inclusion (18\%) and forest, biodiversity and watershed management (16\%). There are no studies found in rural and urban settlement theme. Geographic distribution of CCA studies revealed that over $40 \%$ studies were carried out from central Nepal, while no study was conducted in ten districts of eastern and western Nepal. The study focus was also discrete, and the perception and attitude and impact assessment of climate change were common agendas; however, the drivers of change and options for adaptation were understudied. CCA with multipronged initiatives provide a broader understanding of dynamics and governance of climate change that not only affects rural livelihoods, but also influences regional and global environments and biodiversity.
\end{abstract}

Keywords Climate change adaptation $\cdot$ Research $\cdot$ Adaptation planning $\cdot$ Sustainable development

\section{Introduction}

Climate change is a global inevitable threat to our society (Smith et al. 2011; Cosofret and Bouriaud 2019). Climate change assessment report in the Hindu Kush Himalaya revealed that even if global warming is limited to $1.5^{\circ} \mathrm{C}$ by 2100 , there would be around $2{ }^{\circ} \mathrm{C}$ rise in

Ripu Mardhan Kunwar

ripukunwar@gmail.com

1 Agriculture and Forestry University, 44200 Bharatpur, Nepal

2 Gandaki University, Pokhara 33700, Nepal

3 University of Southern Queensland, Toowoomba 4350, Australia

4 Ethnobotanical Society, Kathmandu 44600, Nepal 
temperature in the Himalayas due to elevation-dependent warming, a phenomenon where mountains experience rapid and extreme changes with rise in temperature Wester et al. (2019). The increase in global surface temperature is a contributor to changing precipitation patterns, and climate warming is associated with declines in snow, ice cover, glaciers and permafrost (Hock et al. 2019). Due to climate variability and extreme weather events, it is estimated that Nepal losses ca. NRs $60 \mathrm{Bl} /$ year in 2017 prices (NPC 2017) which is about $2 \%$ of GDP per year. Climate change brings greater water stress and scarcity and poses a real threat to food security (IIED 2015). The aftermath of these climate change impacts curtailed the health, hygiene, habitat and hospitality of environment and livelihood. Poor understanding of impacts of climate change on species and ecosystems, weak assessment and learning pool, and inadequate capacity are some of the major gaps and issues in effective implementation of climate change adaptation and mitigation programmes (Kunwar 2020).

To address this challenge, climate change adaptation has become a priority alongside mitigation in global, national and local policy agendas. The IPCC AR5 (2014) defines adaptation as "the process of adjustment to actual or expected climate and its effects". Despite the abundance of adaptation strategies, progress in turning these measures into implementation is feeble (Swart et al. 2014). In parallel to the policy progress, scientific endeavours on understanding different dimensions of climate change adaptation (CCA) have increased substantially in recent years (Berrang-Ford et al. 2011; Thapa et al. 2020). The IPCC AR5 working group II synthesized the most recent assessment of the scientific progress on adaptation. Adaptation research and practice too often overlooks the wider social context within which climate change is experienced (Ensor et al. 2019). Adaptation research and practice must expand and be rooted in a broader framing to address the context and drivers of climate change, and, consequently, to be opened up to CCA options (Ely et al. 2014).

The distribution of CCA research is mostly in developed world and there is limited research in developing and least developed countries (Mertz et al. 2009; Ford et al. 2015). IPCC (2007) AR4 Report designated the Himalaya including Nepal as a "white spot" because of the limited number of scientific studies conducted. The need for adaptation varies from place to place, depending on the sensitivity and vulnerability to the environmental impacts (Sarkodie and Strezov 2019). The research on CCA is limited in Nepal resulting in daunting response to climate change impacts (Bhattacharjee et al. 2017). Adaptation challenges grow with the magnitude and the rate of climate change, and confine in the areas where the management strategies are disintegrated. Thus, adaptation is especially important in developing countries where the resources are limited and the effects of climate change are compounded (UNFCCC 2011).

The Paris Agreement (PA) (2015) with the aim to offset the threat of climate change by maintaining global temperature well below $2{ }^{\circ} \mathrm{C}$ has resulted in a large number of publications on CCA and Nepal was not exempt. The key national policy frameworks such as the Three-Year Plan Approach Paper (2011-2013), National Adaptation Programme of Action (NAPA) (2010), LAPA (2011) and Climate Change Policy (2011) were early measures enabling the CCA research and investment environment (GoN 2019). In 2011, Nepal prepared the National Framework on LAPA to implement the adaptation actions at local level and to ensure integration of CCA into every level of the national planning process (Regmi and Karki 2010; Regmi and Bhandari 2012) that opened up the plethora of spaces for CCA research. The research was facilitated by the project investment and funding (Karki et al. 2021a). Research to support adaptation needs an advancement that better connects the societal needs, sustainability, science and study (S4) (Moser 2010; Deppisch and Hasibovic 2013; Swart et al. 2014). A multidisciplinary or an interdisciplinary approach, where disciplinary knowledge is, respectively, exchanged or integrated, is deemed necessary in order 
to ensure that resources are being appropriately invested, researches are undertaken and knowledge of current status and gaps in adaptation action is updated frequently and used to inform governments at all levels (Berrang-Ford et al. 2011; Biesbroek et al. 2013). In this connection, this paper (1) reviews the CCA researches in Nepal published between 2010 and 2020, (2) identifies the research knowledge and gaps and (3) concludes the study with way forwards for the advancement of adaptation planning (Wang et al. 2018). This paper provides a meta-analysis of existing CCA researches, policies and practices to determine patterns and trends that can enable future progress in this field, specifically in Nepal.

\section{Methodology}

This paper is based on review information generated from a systematic literature appraisal of peer-reviewed published journal papers available via Google Scholar and a limited selection of grey literature documents. "Grey" literature documents such as government policy documents, project reports and university theses that do not pass through the scientific peer-reviewed system but relevant to this paper were collected for analysis. Grey literatures selected are important as these basically follow external reviews and extensive multi-level consultations (proxy for a peer-reviewed process) (Lesnikowski et al. 2013). An open web search research review and text mining were the foundation pillars of this research. Text mining pools the researches according to text characters, search string and sentence structure (Scherf et al. 2005; Regmi and Shrestha 2018) and this is an efficient tool to sort out the relevant literature for the review (Thomas et al., 2011). As the COVID19 pandemic limited the visits to institutions and libraries, the systematic web search was considered important and intensively adopted following Vij et al. (2017).

Systematic review, being a scope for conducting both quantitative and qualitative analyses of trends in the literature while providing essential details on the review procedures applied, was used in validating interpretation and replicating the study to test interpretation (Berrang-Ford et al. 2011; Biesbroek et al. 2013). The review focussed on literature published between January 2010 and July 2020 and was limited to English language (Fig. 1). The keywords used for searching ('Nepal', 'climate change adaptation', 'forest', 'agriculture', 'disaster risk reduction', 'resilience', and 'health') were referenced from Nepal National Adaptation Plan (NAP) documents. Only seven keywords limited the search resulted in limited literature on rural urban settlement, water and energy, finance, GESI and research. Using the keywords, and applying the inclusion and exclusion criteria (Table 1) (Sud et al. 2015), a total of 235 research articles were identified and their contents were reviewed. This review was facilitated by Backward Reference Searching (Weirtz et al. 2016).

After making extensive review (studies carried out in Nepal and to be precise between January 2010 and July 2020), the proper documentation and assessment were carried out in order to elucidate the way forwards based on the lessons learned and best practices. The analysis also followed a qualitative method with quantitative steps since the qualitative information was quantified and measured for qualitative content analysis (QCA) (Mayring 2014). The content analysis pursued based on the number of publications at spatial (at district level), temporal (annual average between 2010 and 2020), thematic level (12 themes guided by NCCP-2019) (Supplementary file 1) and value-based (strength, weakness and way forward). The intensive reviews appraised the themes, adaptation actions, research areas, inputs, beneficiaries, strength, gaps, 


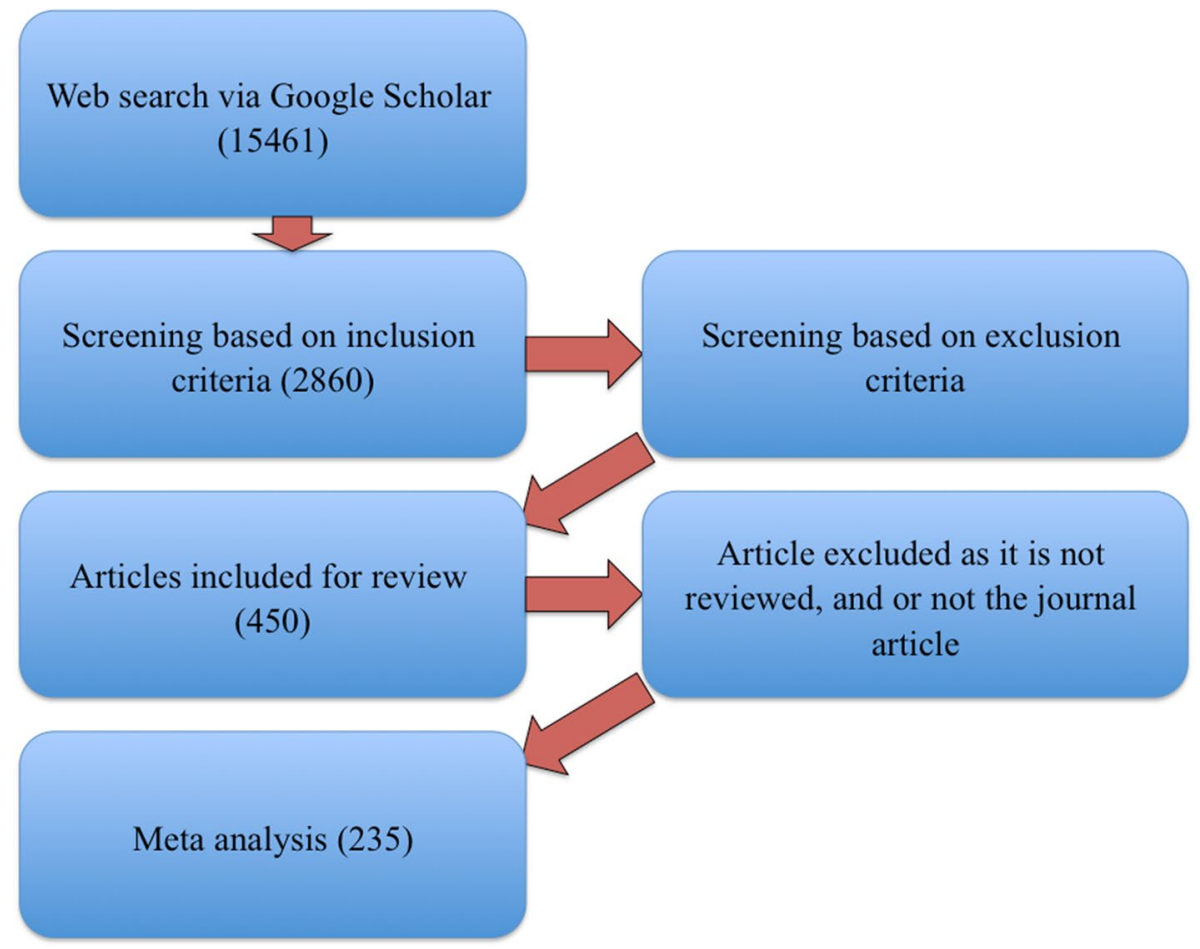

Fig. 1 Process of systematic review and meta-analysis (qualified number of literature is in parentheses)

Table 1 Inclusion and exclusion criteria

Criteria included Criteria excluded

Literature published between 2010 and 31.07.2020

Policy and practice focus on climate change adaptation

Reviews, articles and grey literature

Relevant to climate change adaptation research

Literature relevant to Nepal and its geography
Literature published before 2010 and after July 2020

Scientific assessment, model validation, methodological refine

Proceedings, editorial, letters

Non climate-related content

Any research that was not focused on Nepal or a region within Nepal

Peer-reviewed documents and documents underwent News, reports and unreviewed documents external reviews and multi-level consultations

lessons and etc. With this review, this communication contributed to a growing body of literature that argues for the need to evaluate adaptation researches that eventually eases advancement of climate change adaptation planning in Nepal. 


\section{Results and discussion}

Of the $235(N=235)$ articles that were analysed, $87(37 \%)$ were from the agriculture and food security, a leading theme. There were 66 studies exclusively on the agriculture and food security, whereas the other 21 were dealt on both agriculture and food security and other themes. Profound articles from the agriculture and food security could be the influence of conventional research pattern. Earlier CCA researches were dealt more on rural adaptation practices mostly related to agriculture and food productivity (Gentle and Maraseni 2012; Chhetri et al. 2012). Theme gender equality and social inclusion (GESI) narrowly overtaken the forest, biodiversity and watershed management theme $(38,16.1 \%)$ with $42,17.8 \%$. Disaster risk reduction (DRR) $(33,14 \%)$, water and energy $(28,11.9 \%)$, awareness raising and capacity development $(23,9.7 \%)$ and research and technology development-related articles $(13,5.5 \%)$ made the consecutive positions. Drinking water, sanitation and hygiene (WASH) $(5,2.1 \%)$, climate finance $(6,2.5 \%)$, tourism, natural and cultural heritage $(5,2.1 \%)$ and transport and infrastructure $(1,0.4 \%)$ themes each had less than 10 articles. We could not found the CCA studies related to rural and urban settlement and this could be an aftermath of limited search string. Only seven search strings were used for this review and none was related to rural and urban settlement. There were 44 researches with focus on multiple themes. Some of the cross-cutting themes such as GESI, DRR, Awareness Raising and Capacity Building were co-studied with major themes related to forestry, agriculture, water, energy, health and etc.

\subsection{Climate change adaptation research in the last 10 years}

The last 10 years (2010-2020) evidenced an increase in the number of scientific publications on CCA in Nepal although there is no linearity over the period. Despite the erratic pattern, a consistent increase was observed between 2015 and 2020. During the peak period (2015-2020), the average number of published articles was 32.8/year, while in the sample year (2010-2020), the average was 25.4/year ( $\min 6$ in 2010 and $\max 41$ in 2018) (Fig. 2). The pattern was found declining after 2018. However, we also need to admit that there could be different patterns as the sample was limited only up to July 2020.

Analysis of the publication trend revealed that CCA publication gradually gained momentum between 2010 and 2015 and attained peak at 2018. As adaptation to climate change gained a prominent place next to mitigation on global, national and local policy agendas after 2010 (Swart et al. 2014), the successive adaptation protocols and researches were in place as a result. The resultant pattern was also supported by UNFCCC initiatives. The COP-16 Cancun, Mexico (2010) adopted the Cancun Adaptation Framework (CAF) as part of the Cancun Agreements and affirmed to enhance action on adaptation. Between 2009 and 2012, Nepal received a total commitment of approximately US\$236 ml (Oxfam Nepal 2014), and between 2011 and 2016, a total of US\$ $151.04 \mathrm{ml}$ was pledged as international assistance for adaptation actions. It has been estimated that approximately US\$ $652 \mathrm{ml}$ of international public grant finance for climate change-related activities has been made available until 2016 (MoALD 2019). The dedicated funding for CCA through the projects such Hariyo Ban Programme (2011-2015), Multi Stakeholder Forestry Programme (2011-2016), NCCSP (2013-2017) and Ecosystem-Based AdaptationI (2011-2016) were crucial in averting climate action into CCA (Seiff 2017; Maharjan and Maharjan 2020). These major projects have provided the opportunity to receive CCA 


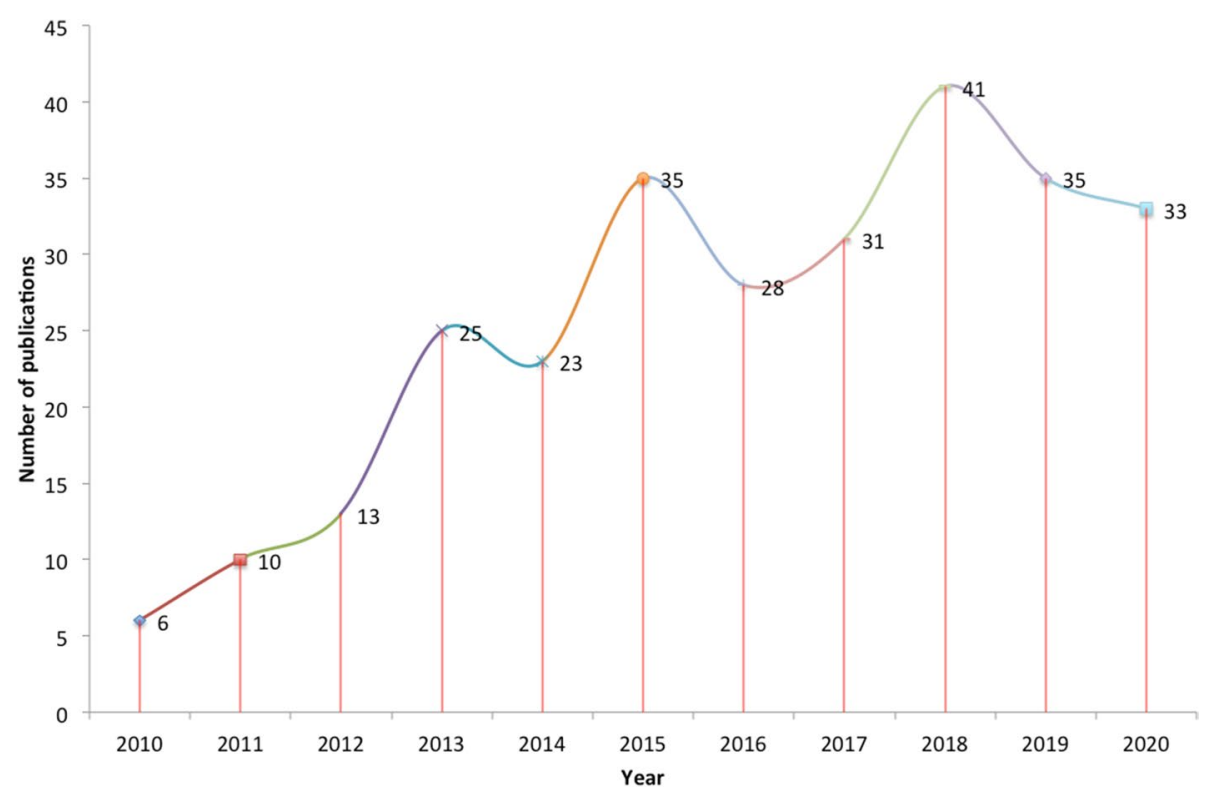

Fig. 2 Distribution of CCA publication over the study period (2010-2020)

funding and this has invigorated researchers, resource managers and academia, whom have developed various tools and techniques for climate change adaptation research. Early CCA publications were dealt on rural adaptation practices mostly related to agriculture (Gentle and Maraseni 2012; Chhetri et al. 2012). Other seminal CCA publications provided the information on perception of climate change, the needs for adaptation (Manandhar et al. 2011; Becken et al. 2013; Khanal 2014).

The research and publication on CCA in Nepal continued spiking until 2018. Cosofret and Bouriaud (2019) found similar trend in publications at the global scale. The worldwide climate change budget cut (Zhang et al. 2017) and spill-over effect helped detract the research over adaptation resulting in less number of publications in post 2018 (Nelson et al. 2009). We argued that the proliferation is based on availability of funding, literature, datasets and growth in policy environment along with the encouragement of IPCC AR5. Robinson (2020) reported the increase attributed by the stronger research base, the availability of datasets and more climate-friendly agreements and commitments. Global trend on the publication of CCA remained increasing; however, there is also some paucity (Nalau and Verrall 2021).

\subsection{Themes covered by CCA publication}

CCA under the agriculture and food security theme was well studied during 2010 and 2020; however, the most studied foci were perception and attitude survey and impact assessments (Fig. 3). The GESI, DRR and forest, biodiversity and watershed management themes were also frequently studied over the period.

CCA publication in Nepal between 2010 and 2020 showed a distinct feature as theme agriculture and food security was found to be associated with the high number of 


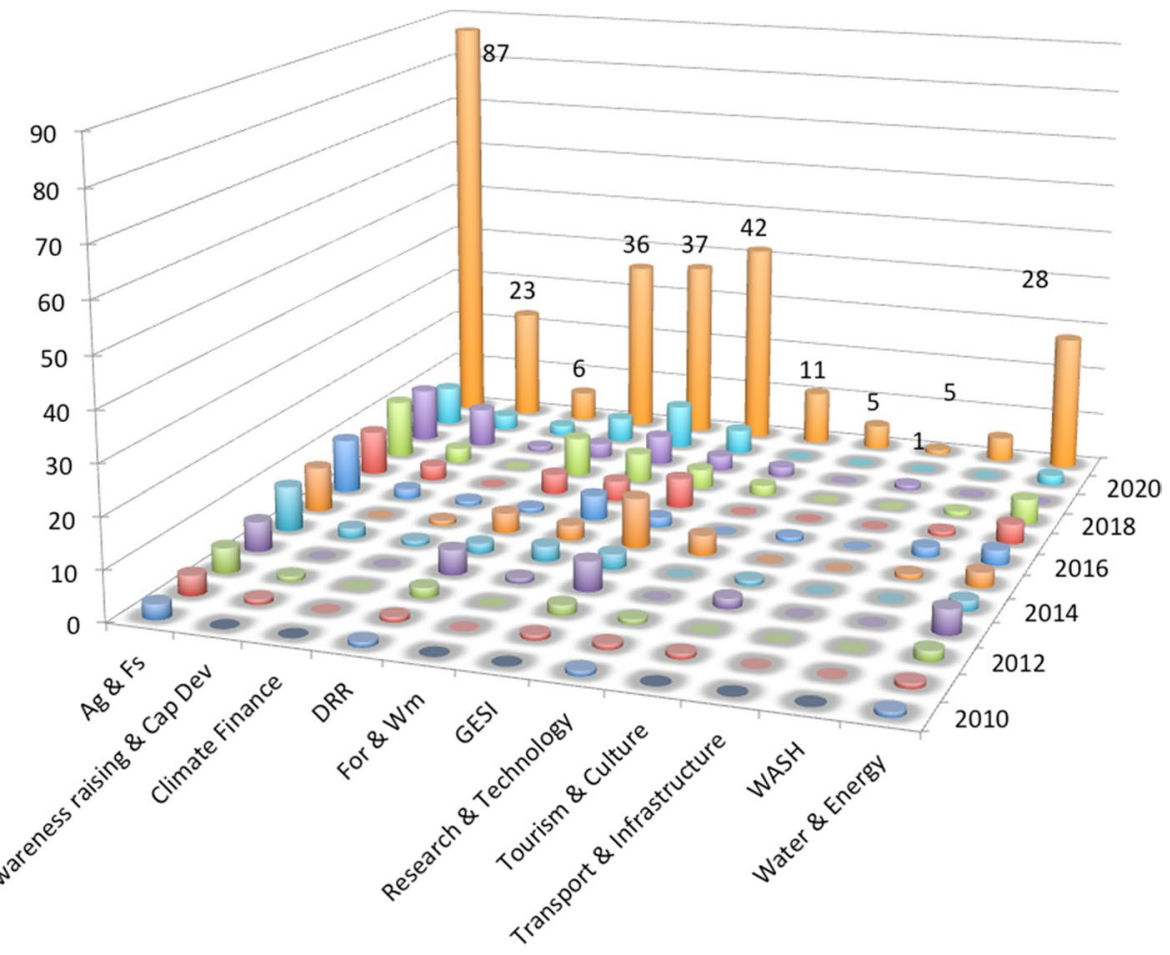

Fig. 3 Number of CCA studies across the themes and over the years

researches and publications. Ensor et al. (2019) reviewed the literature and found the similar focus to agricultural sector in Nepal. This skew is even more contrast at global scale and revealed that CCA studies are mostly focused on agriculture and food security (AleixandreBenavent et al. 2017; Nalau and Verrall 2021). The theme GESI, forest, biodiversity and watershed management and DRR followed the pattern. In the middle of the last decade, Nepal was trembled by 7.8 Richter scale earthquake urging more investment and research on disaster (Rimal et al. 2017). Floods, landslides and drought are major natural hazards causing over 500 casualties and the same number of human fatalities in the last 2 years (MoHA 2017), which are likely to get exacerbated in the plight of climate change uncertainties. DRR-related researches and projects were rife in the country in 2016. Increase of research in forest, biodiversity and watershed management could be due to the lobbying for environment and forestry conservation in recent years and the contribution of various series of natural resource management-related projects (e.g. Hariyo Ban I, II, EbA I, II, NCCSP I, II, Himalica). Very few studies considered other themes such as WASH (drinking water, sanitation and hygiene), water and energy, and research and technical and capacity development in CCA.

A systematic review conducted by Dhimal et al. (2015) reported the disparity on WASH and found only 12 publications that considered vector-borne diseases and CCA (Wirtz et al. 2016). The underlying reasons for low yield of publications on health sector could be attributed to weak health system attributed by low investment of the country having a difficult geographical terrain, and no linkages established between climate variables with 
relevant vectors. In recent years, research on sustainable green development, energy, technology and water sector have gained momentum (Leal-Filho et al. 2018; Nalau and Verrall 2021). Contrarily, we could not find any CCA research studies themed on rural and urban settlements. While advancing CCA, the emerging issues and solutions shaped by socioecological system and community-specific attributes are to be addressed (Pandey et al. 2015; Chaudhary et al. 2016). Livelihood, vulnerability and risk assessment, and resilience building initiatives pertaining to climate change adaptation are imperative in Nepal (Karki et al. 2021b).

\subsection{Spatial distribution of CCA publication across Nepal}

Analysis of CCA publication at spatial scale was carried out to forward findings to guide long-term adaptation planning. The number and themes covered by the studies and publications were quantified by intensity and diversity indices. The number of publications (intensity) and coverage of themes (diversity) were taken into account to map the research/ publication. Intensification was defined as the number of research publications and diversification as variety of themes covered in publication. From the 235 publications sampled, the maximum number of publications (large circles in Fig. 4) and the wide cover (>7 themes, green colour) were from Kaski $(27,8)$, Mustang $(24,8)$, Chitwan $(24,7)$ and Gorkha $(19,6)$ districts. From 2010 to 2020, there were no CCA publications from 10 districts, namely Bhojpur, Dhankuta, Morang, Panchthar, Tehrathum and Siraha in eastern Nepal, and Jajarkot, Rolpa, Rukum E, Rukum W and Salyan in western Nepal.

There is a great disparity in geographic distribution of CCA research and publication in Nepal and this could be a result of funded project-driven researches and the

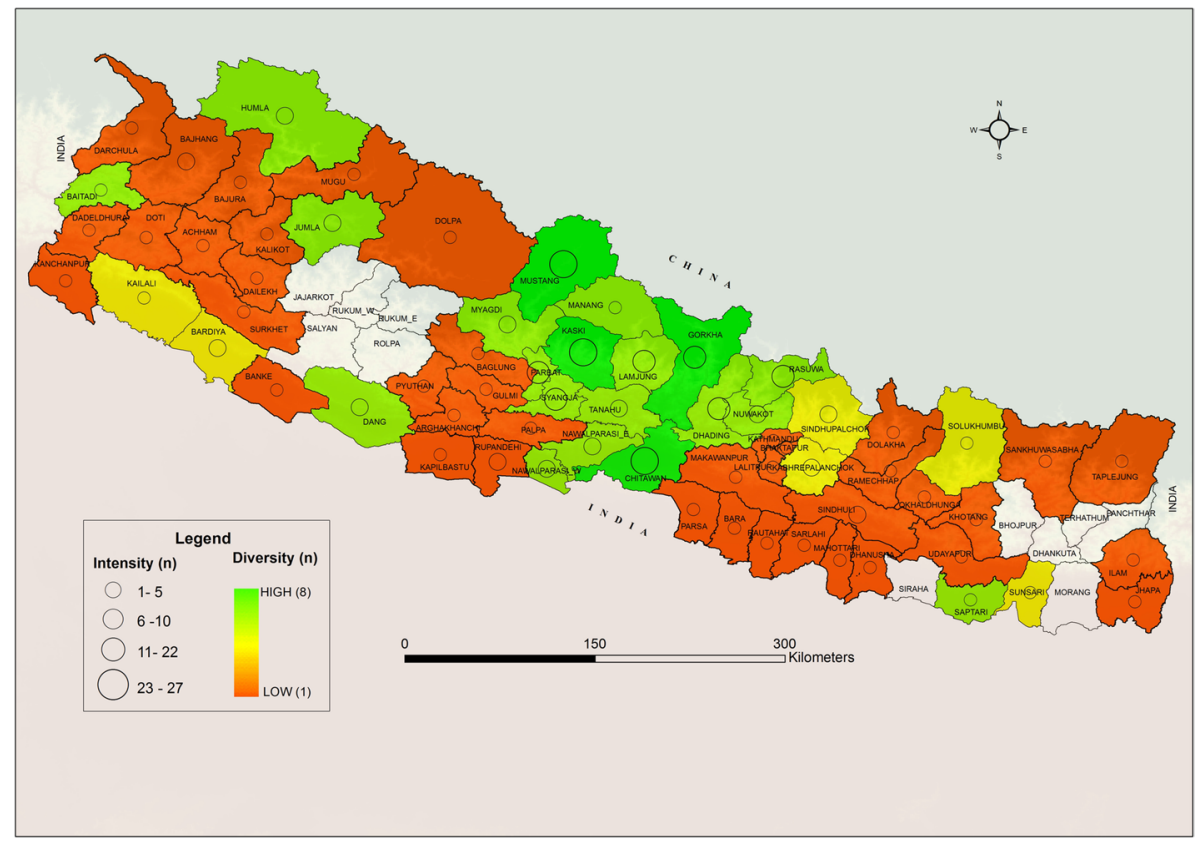

Fig. 4 The number of themes covered by researches in each district of Nepal 
associated publications. Funding opportunity is attributed to the number researches and publications (Acharya et al. 2019). About $42 \%$ of the publications were from four districts, namely Kaski, Chitwan, Mustang and Gorkha. There were 76 CCA projects in Nepal run by the government and non-government actors between 2010 and 2020 (Kunwar 2020). Out of them, almost $13 \%$ projects were exclusively focused in four districts (Kaski, Chitwan, Mustang and Gorkha). Of the four major CCA projects implemented in early last decade, two were confined at central Nepal, resulting in high number of researches and publications from Kaski, Chitwan, Gorkha and Mustang districts.

The corpus of CCA research publication from Kaski and Chitwan districts could be entrenched to the prevailing academic institutions. The research works at the Institute of Forestry-Kaski (founded in 1981) and the Institute of Animal and Agriculture Sciences-Chitwan (founded in 1974) significantly led the outstanding publications on CCA from these two districts. Among the 76 CCA projects, 20 were co-implemented by Local Initiatives for Biodiversity Research and Development (LiBIRD). LiBIRD is a Kaski-based non-governmental organization working largely on CCA on agriculture and food security theme. Similarly, the LAPA was tested through various institutions under "Climate Adaptation Design and Piloting Nepal" (CADPN) project, under which Kaski was one of the pilot districts (Regmi et al. 2016). While the central Nepal was invested more on research and publication, the districts from hills, mountains and eastern Nepal were under-emphasized for CCA research. Bhojpur, Dhankuta, Morang, Panchthar, Tehrathum, Taplejung and Siraha districts in eastern Nepal and Jajarkot, Rolpa, Rukum and Salyan in mid-western hills had no publication aftermath of low investment on CCA research. Among the drivers, inaccessibility to the area could also be a driver of this limitation (Huber 2015). Limited CCA research and studies in mid-western hills curtail the chronic poverty of the area (Gentle et al. 2014; ADB 2017; Mainali and Pricope 2018).

\subsection{Challenges}

The major foci of the researches were perception, attitude and status survey, and consequence focused not on the appraisal of the cause, drivers and options of the CCA. A total of 20 studies out of 235 focussed on perception and attitude survey of climate change. Studies assessing the impact of climate change on biodiversity are rife in Nepal (Bhattacharjee et al. 2017). Moreover, CCA research has mainly focused on aggregated perspectives; this can neglect critical issues of poverty reduction, food security, ethics and the rights of many CCA refugia and other vulnerable communities. Rural mountains, traditional culture and livelihoods have been in the hardest hit (Dhakal and Kattel 2019), but there are least number of researches in comparison (Pandey and Bardsley 2015). These disparities have been constrained by large-scale socio-cultural, and political drivers, especially bureaucratic structures (Sapkota et al. 2019), and other barriers ranging from technical, access, institutional, financial and not yet well integrated development plans (Regmi et al. 2014). The less and discrete researches on CCA could be a reason of inadequate knowledge (Budhathoki et al. 2020) of nexus of research-sciencepractice (Moss et al. 2013). Research helps connect the societal needs, sustainability, science and study (Swart et al. 2014). It links direct adaptation options with scales of decision. It is required to research and develop adaptation measures for ecosystem-based 
adaptation and long-term best practice documentation and service delivery and emphasize the benefits of addressing social inequalities.

\section{Conclusions}

Climate change is comparatively a new domain of science, and adaptation is a craft of science and practice. Localized experience and observation-based climate knowledge is crucial to robust the stock of climate change adaptation science. For this, more action research on agro-ecology, geography and adaptation exercise is essential together with its dissemination at global scale. As climate change continues to challenge sustainable development globally, there is an imperative to have research that analyzes the knowledge of and extent to which climate adaptation is being integrated into regional, national and international policies and practices (Chaudhury et al. 2016). This review contributes to a growing body of theoretical and applied literature conceptualizing how CCA research interventions have developed and interplayed with the different disciplines in Nepal. The present meta-analysis revealed that there are still several challenges. One of the prominent gaps is the underrepresentation of CCA studies from several geographical regions, sectors, themes, needs and options. The CCA research on wide range of scopes provides a broader understanding of CCA dynamics and governance of how CCA will affect livelihood, biodiversity and environment. Further research and publications on drivers and options of CCA and sustainable generation and supply of adaptation services are needed to establish fundamental baseline for advancement of NAP and long-term adaptation planning.

Supplementary Information The online version contains supplementary material available at https://doi. org/10.1007/s11027-021-09991-0.

Acknowledgements We thank the University of Agriculture and Forest for supporting this study. The first author would like to acknowledge the United Nation Environment Programme for providing access to the Nepal National Adaptation Plan database that has served the opportunity to conduct this research. The paper also benefitted with feedback received from numerous scholars. We highly appreciate the editorial support from many individuals and constructive feedback from editor and reviewers, which helped clarify our ideas and improve the manuscript.

Author contribution GK designed the study, carried out the fieldwork, curated the data, wrote the draft and reviewed the final MS. RMK curated and analysed the data, wrote the draft and reviewed the final MS. RPA analysed the data and reviewed the final MS. BB designed the study, and reviewed the draft and final MS. NRD designed the study, and reviewed the draft and final MS.

Data availability Data are available in the supplementary file.

\section{Declarations}

Competing interests The authors declare no competing interests.

\section{References}

Acharya RP, Maraseni T, Cockfield G (2019) Global trend of forest ecosystem services valuation-an analysis of publications. Ecosystem Services 39:100979 
ADB (2017) Country poverty analysis detailed. Nepal. ADB, Manila. https://www.adb.org/sites/default/ files/linked-documents/cps-nep-2013-2017-pa-detailed.pdf

Aleixandre-Benavent R, Aleixandre-Tudó JL, Castelló-Cogollos L, Aleixandre JL (2017) Trends in scientific research on climate change in agriculture and forestry subject areas (2005-2014). J Clean Prod 147:406-418

Becken S, Lama AK, Espiner S (2013) The cultural context of climate change impacts: perceptions among community members in the Annapurna conservation Area. Nepal Environmental Development 8:22-37

Berrang-Ford L, Ford JD, Paterson J (2011) Are we adapting to climate change? Glob Environ Chang 21:25-33. https://doi.org/10.1016/j.gloenvcha.2010.09.012

Bhattacharjee A, Anadón JD, Lohman DJ, Doleck T, Lakhankar T, Shrestha BB, Thapa P, Devkota D, Tiwari S, Jha A (2017) The impact of climate change on biodiversity in Nepal: current knowledge, lacunae, and opportunities. Climate 5:80

Biesbroek GR, Klostermann JEM, Termeer CJAM, Kabat P (2013) On the nature of barriers to CCA. Reg Environ Change 13:1119-1129. https://doi.org/10.1007/s10113-013-0421-y

Budhathoki NK, Paton D, Lassa JA, Zander KK (2020) Assessing farmers' preparedness to cope with the impacts of multiple climate change related hazards in the Tarai lowlands of Nepal. International Journal of Disaster Risk Reduction 49:101656

Chaudhury AS, Ventresca MJ, Thornton TF, Helfgott A, Sova C, Baral P, Rasheed T, Ligthart J (2016) Emerging meta-organizations and adaptation to global climate change: evidence from implementing adaptation in Nepal, Pakistan and Ghana. Glob Environ Chang 38:243-257

Chhetri N, Chaudhary P, Tiwari PR, Yadaw RB (2012) Institutional and technological innovation: understanding agricultural adaptation to climate change in Nepal. Appl Geogr 33:142-150

Coşofreţ C, Bouriaud 1 (2019) Which silvicultural measures are recommended to adapt forests to climate change? A literature review. Bulletin of the Transilvania University of Brasov. Forestry, Wood Industry. Agricultural Food Engineering II Series 12:13-34

Deppisch S, Hasibovic S (2013) Social-ecological resilience thinking as a bridging concept in transdisciplinary research on climate-change adaptation. Nat Hazards 67:117-127

Dhakal B, Kattel RR (2019) Effects of global changes on ecosystems services of multiple natural resources in mountain agricultural landscapes. Sci Total Environ 676:665-682

Ely A, Van Zwanenberg P, Stirling A (2014) Broadening out and opening up technology assessment: approaches to enhance international development, co-ordination and democratization. Res Policy 43(3):505-518. https://doi.org/10.1016/j.respol.2013.09.004

Ensor JE, Wennström P, Bhatterai A, Nightingale AJ, Eriksen S, Sillmann J (2019) Asking the right questions in adaptation research and practice: seeing beyond climate impacts in rural Nepal. Environ Sci Policy 94:227-236

Ford JD, Berrang-Ford L, Bunce A, McKay C, Irwin M, Pearce T (2015) The status of climate change adaptation in Africa and Asia. Reg Environ Change 15(5):801-814

Gentle P, Maraseni TN (2012) Climate change, poverty and livelihoods: adaptation practices by rural mountain communities in Nepal. Environ Sci Policy 21:24-34

Gentle P, Thwaites R, Race D, Alexander K (2014) Differential impacts of climate change on communities in the middle hills region of Nepal. Nat Hazards 74:815-836. https://doi.org/10.1007/ s11069-014-1218-0

GoN (2019) Nepal: status paper for COP 25, CMP 15 and CMA 2. Government of Nepal, Ministry of Forests and Soil Conservation, Kathmandu, Nepal.

Hock R, Rasul G, Adler C, Cáceres B, Gruber S, Hirabayashi Y, Jackson M, Kääb A, Kang S, Kutuzov S, Milner AU, Molau U, Morin S, Orlove B, Steltzer H (2019) High mountain areas; in IPCC special report on the ocean and cryosphere in a changing climate (eds.) HO Pörtner, DC Roberts, V Masson-Delmotte, P Zhai, M Tignor, E Poloczanska, K Mintenbeck, A Alegría, M Nicolai, A Okem, J Petzold, B Rama, NM Weyer (eds.). Geneva, Switzerland: World Meteorological Organization. https://www.ipcc.ch/ srocc/chapter/chapter-2/

Huber S (2015) Accessibility of peripheral areas in Nepal: the role of infrastructure development and environmental constraints as limiting factors. Research Paper, Berlin

IIED (2015) Capacity strengthening in least developed countries (LDCs) for adaptation to climate change (CLACC), http://www.iied.org/capacity- strengthening-least-developed-countries-for- adaptation-climate-change-clacc.

IPCC (2007) AR4 IPCC fourth assessment report: climate change. Writing Team; Pachauri, R.K; and Reisinger, A. Geneva, Switzerland.

IPCC (2014). Climate-resilient pathways: adaptation, mitigation, and sustainable development. In C. B. Field et al. (Eds.), Climate change 2014: impacts, adaptation, and vulnerability. Part A: global and 
sectoral aspects. Contribution of Working Group II, AR5 IPCC (pp. 1101-1131). Cambridge: Cambridge University Press. https://www.ipcc.ch/pdf/assessment- report/ar5/wg2/WGIIAR5-Chap20_ FINAL.pdf.

Karki GK, Bhatta BR, Devkota NR, Acharya R, Kunwar R (2021) Climate change adaptation (CCA) interventions and indicators in Nepal: implications for sustainable adaptation. Sustainability 13(23):13195. https://doi.org/10.3390/su132313195

Karki GK, Bhatta BR, Devkota NR, Kunwar R. (2021b) Climate change adaptation governance in Nepal: a framework for sustainable generation of adaptation services. Banko Janakari 31(2).

Khanal U (2014) Perception and adaptation of the producers to the impacts of climate change in apple production: an assessment of Mustang District of Nepal. Journal of Agriculture and Environment 15:1117. https://doi.org/10.3126/aej.v15i0.19811

Kunwar RM (2020) Study and review CCA interventions and researches in Nepal to plan future investments in adaptation across the key economic sectors: review and synthesize Nepal's past and current adaptation measures and assess their effectiveness for planning and advancing NAP process, Nepal. Component 1 (Final Report). UNEP Nepal GCF-NAP Project.

Leal-Filho W, Morgan EA, Godoy ES, Azeiteiro UM, Bacelar-Nicolau P, Ávila LV, Mac-Lean C, Hugé J (2018) Implementing climate change research at universities: barriers, potential and actions. J Clean Prod 170:269-277

Lesnikowski A, Ford J, Berrang-Ford L, Barrera M, Berry P, Henderson J, Heymann SJ (2013) Nationallevel factors affecting planned, public adaptation to health impacts of climate change. Glob Environ Chang 23(5):1153-1163

Maharjan S, Maharjan K (2020) Exploring perceptions and influences of local stakeholders on climate change adaptation in Central and Western Tarai. Nepal Climate and Development 12(6):575-589. https://doi.org/10.1080/17565529.2019.1664377

Mainali J, Pricope N (2018) Mapping the need for adaptation: assessing drought vulnerability using the livelihood vulnerability index approach in a mid-hill region of Nepal. Climate Dev 11(7):607-622. https:// doi.org/10.1080/17565529.2018.1521329

Manandhar S, Vogt DS, Perret SR, Kazama F (2011) Adapting cropping systems to climate change in Nepal: a cross-regional study of farmers' perception and practices. Reg Environ Change 11:335-348. https://doi.org/10.1007/s10113-010-0137-1

Mayring P (2014) Qualitative content analysis. Klagenfurt, Beltz, Verlag, Theoretical foundation. Basic procedure and software solution

Mertz O, Halsnaes K, Olsen JE, Rasmussen K (2009) Adaptation to climate change in developing countries. Environ Manage 43:743-752. https://doi.org/10.1007/s00267-008-9259-3

MoALD (2019) Integrating climate change adaptation into agriculture sector planning of Nepal: a handbook. Ministry of Agriculture and Livestock Development, UNDP and FAO

MoHA (2017) Ministry of Home Affairs. Nepal Disaster Report 2017: Road to Sendai, Kathmandu: Government of Nepal.

Moser SC (2010) Now more than ever: the need for more societally relevant research on vulnerability and adaptation to climate change. Appl Geogr 30:464-474. https://doi.org/10.1016/j.apgeog.2009.09.003

Moss RH, Meehl GA, Lemos MC, Smith JB, Arnold JR, Arnott JC et al (2013) Hell and high water: practice-relevant adaptation science. Science 342:696-698. https://doi.org/10.1126/science.1239569

Nalau J, Verrall B (2021) Mapping the evolution and current trends in climate change adaptation science. Climate Risk Management 32:100290

Nelson et al (2009) Climate change: impact on agriculture and cost of adaptation. International Food Policy Research Institute, W. DC, USA.

NPC (2017) Nepal flood 2017: post flood recovery needs assessment, Kathmandu: Government of Nepal.

Oxfam Nepal (2014) Stocktaking study on climate change adaptation finance in Nepal. Oxfam Country Office Nepal.

Pandey R, Bardsley DK (2015) Social-ecological vulnerability to climate change in the Nepali Himalaya. Appl Geogr 64:74-86

Regmi BR, Bhandari D (2012) Climate change governance and funding dilemma in Nepal. TMC Academic Journal 7(1):14

Regmi BR, Karki G (2010) Local adaptation plans in Nepal. TIEMPO 76:21-25. www. tiempocyberclimate.org

Regmi BR, Shrestha K (2018) Policy gaps and institutional arrangements for water resources management in Nepal. HI-AWARE Working Paper 16/2018. Kathmandu: HI-AWARE

Regmi BR, Star C, Leal-Filho W (2016) Effectiveness of the local adaptation plan of action to support climate change adaptation in Nepal. Mitig Adapt Strat Glob Change 21:461-478 
Rimal B, Zhang L, Fu D, Kunwar R, Zhai Y (2017) Monitoring urban growth and the Nepal earthquake 2015 for sustainability of Kathmandu Valley. Nepal Land 6(2):42. https://doi.org/10.3390/land6020042

Robinson SA (2020) Climate change adaptation in SIDS: a systematic review of the literature pre and post the IPCC Fifth Assessment Report. Wiley Interdisciplinary Reviews: Climate Change 11:e653

Sapkota P, Keenan RJ, Ojha HR (2019) Co-evolving dynamics in the social-ecological system of community forestry-prospects for ecosystem-based adaptation in the Middle Hills of Nepal. Reg Environ Change 19:179-192. https://doi.org/10.1007/s10113-018-1392-9

Sarkodie SA, Strezov V (2019) Economic, social and governance adaptation readiness for mitigation of climate change vulnerability: evidence from 192 countries. Sci Total Environ 656:150-164

Scherf M, Epple A, Werner T (2005) The next generation of literature analysis: integration of genomic analysis into text mining. Brief Bioinform 6(3):287-297

Seiff A (2017) Adapting to climate change in Nepal: a bold partnership led by Nepal's people makes strides in the climate-vulnerable country. World Wildlife Mag, Spring 2017. https://www.worldwildlife.org/ magazine/issues/spring-2017/articles/adapting-to-climate-change-in-nepal

Smith MS, Horrocks L, Harvey A, Hamilton C (2011) Rethinking adaptation for a $4^{\circ} \mathrm{C}$ world. Philos Trans R Soc Math Phys Eng Sci 369:196-216. https://doi.org/10.1098/rsta.2010.0277

Sud R, Mishra A, Varma N, Bhadwal S (2015) Adaptation policy and practice in densely populated glacierfed river basins of South Asia: a systematic review. Regional Environmental Change 15(5): 825-836. Retrieved from http://link.springer.com/article/https://doi.org/10.1007/s10113-014-0711-z.

Swart R, Biesbroek R, CapelaLourenço T (2014) Science of adaptation to climate change and science for adaptation. Front Environ Sci 2:29. https://doi.org/10.3389/fenvs.2014.00029

Thapa S, Li B, Fu D, Shi X, Tang B, Qi H, Wang K (2020) Trend analysis of climatic variables and their relation to snow cover and water availability in the Central Himalayas: a case study of Langtang Basin, Nepal. Theoretical and Applied Climatology 1-13.

Thomas J, McNaught J, Ananiadou S (2011) Applications of text mining within systematic reviews. Research Synthesis Methods 2(1):1-14

UNFCCC (2011) Identification and implementation of medium- and long-term adaptation activities in least developed countries. Technical paper FCCC/TP/2011/7, Least Developed Countries expert Group, UNFCCC: Bonn, Germany. Available at <http://unfccc.int/resource/ docs/2011/tp/07.pdf>.

Vij S et al (2017) Climate adaptation approaches and key policy characteristics: cases from South Asia. Environ Sci Policy 78:58-65

Wang Z, Zhao Y, Wang B (2018) A bibliometric analysis of climate change adaptation based on massive research literature data. J Clean Prod 199:1072-1082

Wirtz JG, Hayes JL, Shan Y (2016). Looking backward, looking forward: a systematic review of 20 years of research and commentary. Journal of Advertising Education 8-21.

Wester P, Mishra A, Mukherji A, Shrestha AB (eds) (2019) The Hindu Kush Himalaya assessment-mountains, climate change, sustainability and people Springer Nature Switzerland.

Zhang YX, Chao QC, Zheng QH, Huang L (2017) The withdrawal of the U.S. from the Paris Agreement and its impact on global climate change governance. Advances in Climate Change Research 8(4):213-219

Publisher's Note Springer Nature remains neutral with regard to jurisdictional claims in published maps and institutional affiliations. 